\title{
Incidence of early neonatal hyperbilirubinemia in ABO incompatibility and cord bilirubin as a predictor for phototherapy
}

\author{
Maya Menon ${ }^{1}$, Sreejyothi $G^{2}$, Raveendranath $K^{3}$ \\ ${ }^{1}$ Dr. Maya Menon Associate Professor, ${ }^{2}$ Dr. Sreejyothi. G Assistant Professor, ${ }^{3}$ Dr. Raveendranath. K, Professor and \\ HOD. All affiliated with Department of Pediatrics, SUT Academy of Medical Sciences, Trivandrum, Kerala, India.
}

Address for Correspondence: Dr. Maya Menon, dr.mayamenon94@gmail.com

\begin{abstract}
Neonatal Hyperbilirubinemia is a common condition in neonates and the most common pathological cause leading to hyperbilirubinemia is $\mathrm{Rh}$ or $\mathrm{ABO}$ incompatibility. Although most newborns with jaundice are otherwise healthy, the greatest risk associated with indirect hyperbilirubinemia is the development of bilirubin induced neurologic dysfunction which typically occurs with higher indirect bilirubin levels. Aim of the Study: This study was done to (1) Find out the incidence of early hyperbilirubinemia and need for phototherapy in babies born to O+ve mother and (2) Cord Bilirubin as a marker for early phototherapy in ABO blood group incompatibility. Method : This was a prospective cohort study which included 50 consecutive term appropriate for gestational age babies with blood group either $\mathrm{A}$ or $\mathrm{B}$ born to $\mathrm{O}+\mathrm{ve}$ mother as cases and another 50 consecutive term appropriate for gestationalage babies with $\mathrm{O}+\mathrm{ve}$ blood group born to O+ve mother served as control. Result: $88 \%$ of the babies in the case group required phototherapy for $>24$ hours whereas in the control group only 55\% required phototherapy for $>24 \mathrm{hrs}$. Based on statistical analysis, there was a probability that the newborns who needed early phototherapy had a cord bilirubin 2.05 or more. Conclusion: It may be concluded that babies with ABO incompatibility needed early and prolonged treatment compared to controls. A cord bilirubin above 2.05 can predict the need for treatment.
\end{abstract}

Keywords: Neonatal hyperbilirubinemia, Cord bilirubin, ABO incompatability, Phototherapy, Neonatal Jaundice

\section{Introduction}

Neonatal hyperbilirubinemia is one of the most common conditions that require medical attention in newborn. Jaundice is observed during the first week after birth in $60 \%$ term infants and $80 \%$ of preterm infants [1,2,3]. Although pathological jaundice was almost synonymous with $\mathrm{Rh}$ isoimmunisation, other causes like ABO incompatibility (most common being OAI) Red cell membrane defects (hereditary spherocytosis), Redcells enzyme defects (i.e. G6PD def), thalassemias etc. can contribute to significant number of neonates with pathological jaundice [4].

ABO hemolytic disease is the most common blood group incompatible hemolytic process of the newborn period and a major contributor of neonatal jaundice [5]. In general $15-25 \%$ of all maternal fetal pairs are $\mathrm{ABO}$ incompatible $[4,5]$ but $\mathrm{ABO}$ hemolytic disease is confined to roughly $1 \%$ of such $\mathrm{O}$ group women who

Manuscript received: $4^{\text {th }}$ March 2016

Reviewed: $14^{\text {th }}$ March 2016

Author Corrected; $25^{\text {th }}$ March 2016

Accepted for Publication: 12 $2^{\text {th }}$ April 2016 have antenatal high titre antibodies. ABO isoagglutinins are present in the sera of all individuals whose red cells lack the corresponding antigen and are usually of the IgM class [4,6]. High titres of $\operatorname{IgG}$ antibodies are more likely to occur in group $\mathrm{O}$ individuals than Group A (or) Group B individuals and increased antibody production after antigenic stimulation can occur. Consequently group $\mathrm{O}$ mothers with potent $\mathrm{IgG}$ anti $\mathrm{A}, \mathrm{B}$ or $\mathrm{AB}$ are at greatest risk of having affected infants. Among Group $\mathrm{A}$ or $\mathrm{B}$ infants born to group $\mathrm{O}$ mothers, $30-50 \%$ have detectable maternal IgG antibody bound to their red cells compared to $5 \%$ among all infants. Because ABO IgG antibodies can occur without prior red cell exposure they can result in hemolytic disease of newborn even in first pregnancy $[6,7]$.

Early discharge of healthy term newborn after delivery has become a common practice because of medical, social and economical reasons. The most common cause for readmission during the early neonatal period is hyperbilirubinema. Such readmissions besides 
involving extra expenses for both family and institution, also exposes a healthy newborn to the hospital environment in addition to causing emotional problems. Universal follow up within 1-2 days of early discharge, umbilical cord bilirubin concentration at birth, routine predischarge bilirubin [8], transcutaneous bilirubin measurement as well as universal clinical assessment of risk factors for developing Jaundice are various strategies to predict significant hyperbilirubinema.

Early identification of high risk newborn is important to institute early treatment and prevention of bilirubin induced neurological dysfunction. Kernicterus although infrequent has atleast 10\% mortality and atleast 70\% [9] long term morbidity. Studies showed that phototherapy had an absolute risk reduction rate of $10 \%$ to $17 \%$ for prevention of serum bilirubin levels higher than $20 \mathrm{mg} / \mathrm{dl}$ in healthy infants with jaundice. There is no evidence to suggest that phototherapy for neonatal hyperbrilirubinemia has any long term adverse neurodevelopmental effects [9].

So it is desirable to be able to predict the risk of jaundice in order to implement early treatment and thereby minimize the risk of bilirubin dependent brain damage.

Our study was done to find out the incidence of hyperbilirubinemia in babies with blood group either $\mathrm{A}+$ or $\mathrm{B}+$ born to $\mathrm{O}+$ ve mothers and also the usefulness of cord bilirubin as a marker for early phototherapy in ABO blood group incompatibility.

\section{Materials and Methods}

This was a prospective cohort study which included 50 consecutive term appropriate for gestational age babies with blood group either $\mathrm{A}$ or $\mathrm{B}$ born to $\mathrm{O}+$ ve mothers which served as cases and another 50 consecutive term appropriate for gestational age babies with $\mathrm{O}+\mathrm{ve}$ blood group born to $\mathrm{O}+\mathrm{ve}$ mother served as controls. The study was carried out at the delivery room, postnatal ward and NICU of SUT Academy of Medical Sciences, Trivandrum during the 12 month period from January 2015 - December 2015.

\section{Results}

The study group consisted of 50 babies as controls with blood group $\mathrm{O}+\mathrm{ve}$ born to $\mathrm{O}+\mathrm{ve}$ mothers and another 50 babies as cases with blood group either $\mathrm{A}+$ or $\mathrm{B}+$ born to $\mathrm{O}+\mathrm{ve}$ mothers. All babies enrolled as cases were AGA [Table 1]. Out of the cases $52 \%$ were male babies and $48 \%$ were female babies [Table 2].

Of the case group, 32 babies had A blood group and 18 had B blood group [Table 3]. 25 babies in the case group and 22 babies in the control group needed Phototherapy [Table 4].
2. Rh incompatibility

3. Instrumental delivery (forceps and vaccum)

Institutional ethical committee approval and informed consent from parents were taken and babies which satisfied the inclusion criteria were enrolled for our study. Detailed history using a proforma (prenatal history, maternal complications and medications, type of delivery) and physical examination (birth weight, sex, Apgar score, general examination and gestational age by New Ballard's score) were done .

Cord blood was collected for estimating bilirubin, DCT and blood group for all the babies born to mother having $\mathrm{O}+$ ve blood group. The study and control group babies were followed up clinically and $3 \mathrm{ml}$ of venous blood samples were taken at 24, 48, 72hrs for estimating total serum bilirubin and conjugate bilirubin. Serum bilirubin was estimated using diazo method [10]. Guidelines by American Academy Of Pediatrics [11,12] were followed for deciding treatment.

Statistical analysis Control and case groups were compared for different parameters using Chi Square test. Receiver Operated Characteristic (ROC) curve was drawn for cord bilirubin to elucidate a cut off value for which the sensitivity and specificity was presented in its percentage along with its confidence interval (CI at $95 \%)$. 
Table 1: Distribution of babies based on Birth weight.

\begin{tabular}{llll}
\hline \multirow{2}{*}{ Birth Weight } & Group & Total \\
\cline { 2 - 4 } & Control & Cases & 99 \\
\hline \multirow{2}{*}{$2.5-4.0$} & 49 & 50 & $99.00 \%$ \\
\hline$>4.0 \mathrm{Kg}$ & $98.00 \%$ & $100.00 \%$ & 1 \\
& 1 & & $1.00 \%$ \\
\hline Total & $2.00 \%$ & 50 & 100 \\
\hline Chi Square: $1.010 ; \mathrm{P}>0.05$ & 50 & & \\
\hline
\end{tabular}

Table 2: Distribution based on sex.

\begin{tabular}{llll}
\hline \multirow{2}{*}{ Gender of Baby } & Group & Total \\
\cline { 2 - 3 } & Control & Cases & 60 \\
\hline \multirow{2}{*}{ Male } & 34 & 26 & $60.00 \%$ \\
\hline \multirow{2}{*}{ Female } & $68.00 \%$ & $52.00 \%$ & 40 \\
& 16 & 24 & $40.00 \%$ \\
\hline Total & $32.00 \%$ & $48.00 \%$ & 100 \\
\hline Chi Square: $2.667 ; \mathrm{P}>0.05$ & 50 & 50 & \\
\hline
\end{tabular}

Table-3: Distribution of cases according to blood group.

\begin{tabular}{llll}
\hline \multirow{2}{*}{ Blood Group of Baby } & Group & \multicolumn{2}{c}{ Total } \\
\cline { 2 - 4 } & Control & Cases & 50 \\
$\mathrm{O}$ & 50 & & $50.00 \%$ \\
\hline $\mathrm{A}$ & $100.00 \%$ & 32 & 32 \\
& & $64.00 \%$ & $32.00 \%$ \\
\hline $\mathrm{B}$ & & 18 & 18 \\
& & $36.00 \%$ & $18.00 \%$ \\
\hline Total & 50 & 50 & 100 \\
\hline Chi Square: $100.000 ; \mathrm{P}<0.001$ & & & \\
\hline
\end{tabular}

Table 4: showing no: of babies in case and control group who needed phototherapy.

\begin{tabular}{llll}
\hline \multirow{2}{*}{ Treatment } & Group & Total \\
\cline { 2 - 3 } & Control & Cases & 53 \\
\multirow{2}{*}{ Nil } & 28 & 25 & $53.00 \%$ \\
\hline \multirow{2}{*}{ Yes } & $56.00 \%$ & $50.00 \%$ & 47 \\
& 22 & 25 & $47.00 \%$ \\
\hline Total & $44.00 \%$ & $50.00 \%$ & 100 \\
\hline Chi Square: $0.361 ; \mathrm{P}>0.05$ & 50 & 50 & \\
\hline
\end{tabular}

Regarding the initiation of phototherapy fig. 1 shows $16 \%$ of babies in the case group needed phototherapy within 24 hrs, $64 \%$ in $24-48 \mathrm{hrs}$ and $20 \%$ needed phototherapy after 48 hours.

In the control group, majority of the babies $(82 \%)$ received phototherapy after $48 \mathrm{hrs}$. 


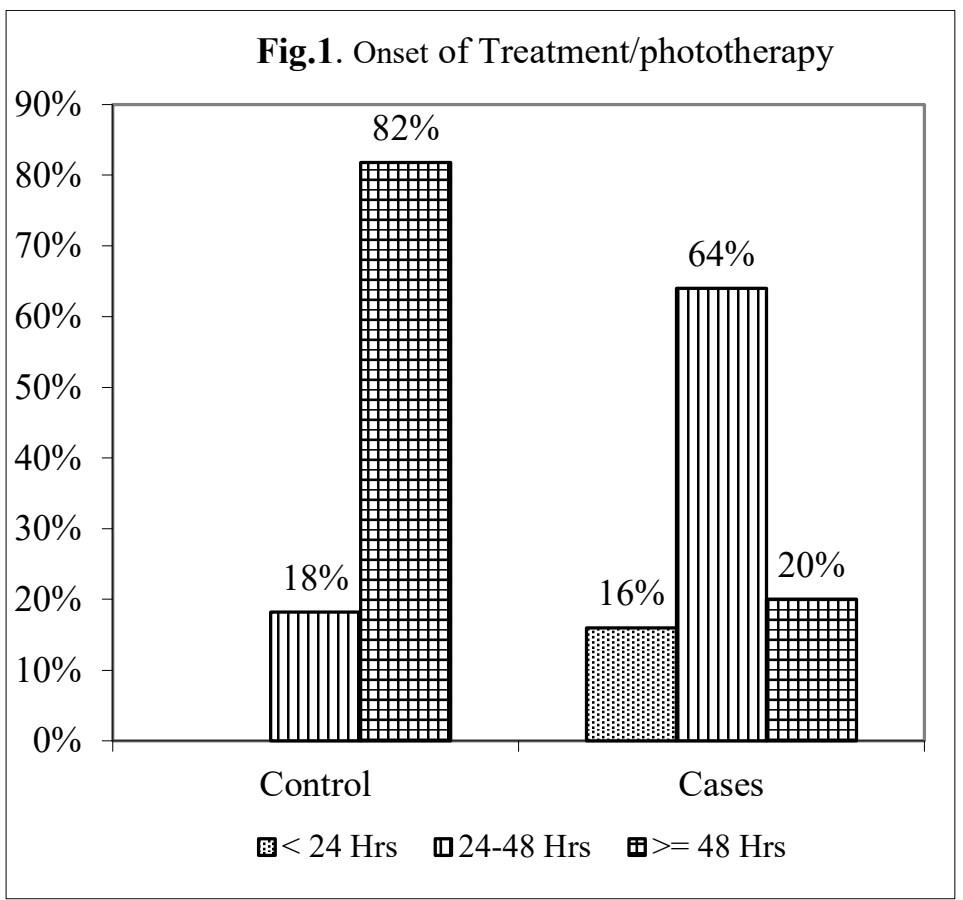

Fig. 2 Shows $88 \%$ of babies in the case group needed phototherapy for more than 24 hours and $8 \%$ needed phototherapy for more than 72 hours. None of the babies in the control group required treatment for more than 72 hours.

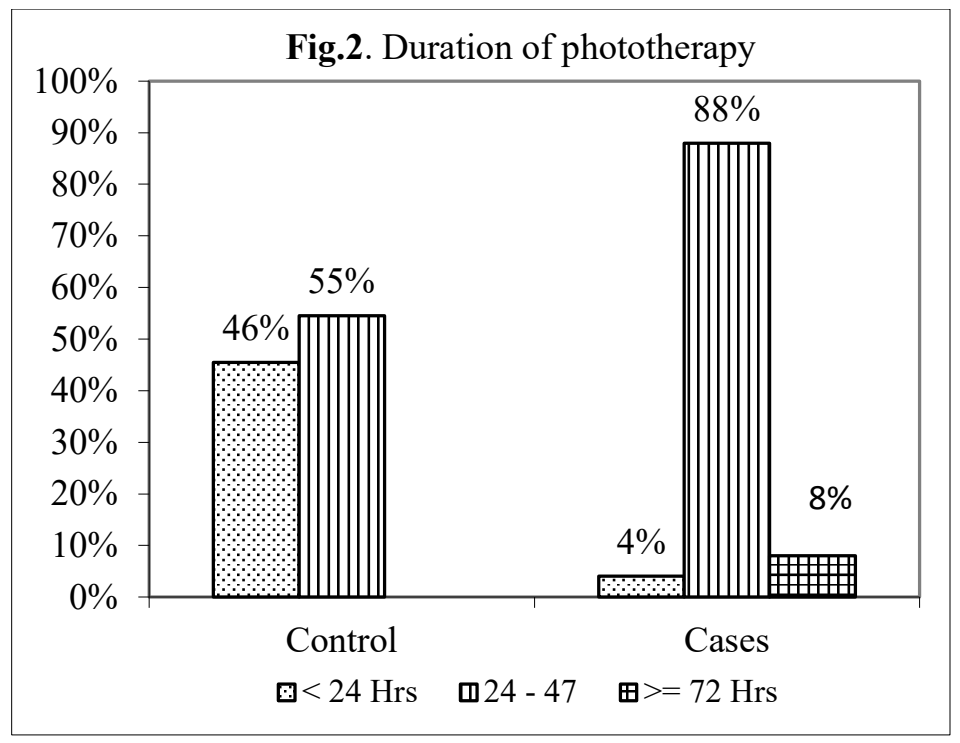

Table 5: Cut off points for total cord bilirubin for Predicting phototherapy.

\begin{tabular}{|c|c|c|c|c|}
\hline $\begin{array}{l}\text { Cord } \\
\text { Positive if }\end{array}$ & Bilirubin & Sensitivity (\%) & Specificity (\%) & $95 \%$ CI \\
\hline 2.05 & & 78 & 80 & \multirow{4}{*}{$78.1-93.3$} \\
\hline 2.15 & & 70 & 86 & \\
\hline 2.25 & & 64 & 90 & \\
\hline 2.35 & & 62 & 94 & \\
\hline
\end{tabular}


The positive likelihood ratio is computed for each cut off point as sensitivity / 1-Specificity. A high positive likelihood ratio is more important for a diagnostic test than for a screening test. Receiver operating characteristic (ROC) curve in fig: 3 shows that area under the curve was 0.857 of total area; $\mathrm{P}<0.001$ indicating the usefulness of test in predicting the need for phototherapy. Thus a cord bilirubin level above 2.05 can predict the need for treatment and is statistically significant.

Fig: 3

\section{ROC Curve}

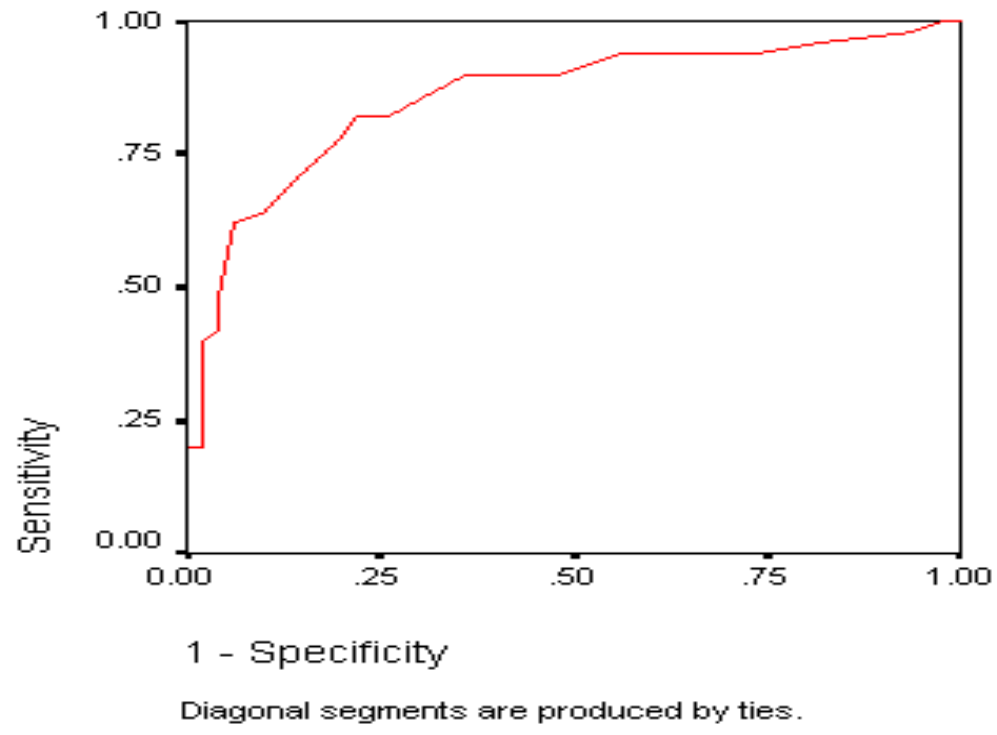

\section{Discussion}

ABO hemolytic disease is the most common blood group incompatible hemolytic process of the newborn period and is the major cause of neonatal jaundice. To rely on clinical observation [13] to notice the jaundiced infants may not be reliable in infants whose skin pigmentation makes the diagnosis of jaundice difficult. So measuring serum bilirubin at different hours of life may be a reasonable compromise. In this study we investigated the incidence of early hyperbilirubinemia and need for phototherapy in babies born to $\mathrm{O}+\mathrm{ve}$ mothers and relation between cord bilirubin level and development of hyperbilirubinemia. Our study population had 50 babies with blood group either $\mathrm{A}$ or $\mathrm{B}$ as cases and $50 \mathrm{O}+\mathrm{ve}$ babies as controls born to $\mathrm{O}+\mathrm{ve}$ mother. The babies enrolled in the case group have equal number of males and females and it was noted that incidence of hyperbilirubinemia is almost the same in both sexes. This shows that neonatal hyperbrilirubinemia is independent of the sex of the neonate. This is in correlation with Amar Taksande et al $[14,15]$ study on 200 neonates who found no correlation between the sex of the neonate and neonatal hyperbilirubinemia. Among the 50 babies in the case group 32 had A+ve blood group and 18 had B+ve blood group.

The incidence of neonatal hyperbilirubinemia was almost the same in the case and control group in our study. This did not agree with the study by Kalakheti et al[1] which showed 2.6 times higher chance of hyperbilirubinemia in babies with $\mathrm{ABO}$ incompatability. Eventhough in our study the incidence of hyperbilirubinemia was almost equal in cases and controls, none of the control group babies required phototherapy in the first 24 hours and majority needed only few hours of phototherapy when compared to cases. According to Wood et al [16] few other factors like inadequate breastfeeds, previous sibling with jaundice, oxytocin induction can also affect neonatal jaundice. These factors may have contributed to the jaundice in these babies.

In our study babies in the case group required early and prolonged phototherapy compared to controls and this is in accordance with the study done by Murray et al [4] which showed that babies with ABO incompatibility 
needed early phototherapy. Bhutani et al [11,12] recommends phototherapy to prevent severe neonatal hyperbilirubinemia.

In our study, by ROC analysis the cut off point for total cord blirubin is 2.05. A critical cut off level of cord bilirubin was predicted in $85 \%$ of newborn. Amar et al[15] found that cord bilirubin $>2 \mathrm{mg} / \mathrm{dl}$ had the highest sensitivity and this critical bilirubin level had a very high negative predictive value. Suresh and Clark [17] found the cord bilirubin could predict the development of jaundice in healthy newborns. Their study showed that bilirubin critical level of $>2 \mathrm{mg} / \mathrm{dl}$ had positive predictive value for detection of developing significant hyperbilirubinemia. The study by Zeiuton et al [2] also showed cord bilirubin as a strong predictor of phototherapy.

\section{Conclusion}

ABO hemolytic disease is one of the important cause of early neonatal hyperbilirubinemia requiring treatment. In our study the cases needed early and prolonged treatment compared to controls. A cord bilirubin level above 2.05 can predict the need for treatment.

\section{Acknowledgement}

1. Dr. Sulekha.B, Prof \& Head, Department of Biochemistry

2. Dr. Radhamony.D, Prof \& Head, Department of Obstretics and Gynaecology

3. Dr. Kurian Mathew Abraham PhD, Mar Thoma College, Tiruvalla

Ethical Approval: Obtained from institutional ethical committee

Funding: Nil

Conflict of Interest: The authors declare no conflict of interest

\section{References}

1. Kalakheti BK, Singh R, Bhatta NK, Karki A, Baral $\mathrm{N}$. Risk of neonatal hyperbilirubinemia in babies born to 'O' positive mothers: a prospective cohort study Kathmandu Univ Med J (KUMJ). 2009 JanMar;7(25):11-5.

2. Zeitoun A, Elhagrasy H, Abdelsatar D. Predictive value of umbilical cord blood bilirubin in neonatal hyperbilirubinemia. Egyptian Pediatric Association Gazette. 2013 Jan;61(1):23-30.doi:10.1016
3. Ambalavanan N, Carlo.W.A. Jaundice and hyperbilirubinemia in the Newborn. In Kliegman RM, Behrman RE, Stanton BF, Schor NF, St Geme III JW, Nelson text book of Peadiatrics: $20^{\text {th }}$ ed. New Delhi Elseviers, 2015: $\quad$ Chapter 102: P 871-872.

4. Murray N, Roberts I. Haemolytic disease of the newborn. Archives of Disease in Childhood - Fetal and Neonatal Edition. 2007;92(2): F83-F88. doi: 10.1136/adc. 2005. 076794

5. Naveen g. Nadig; a. C. Basavaraj early predictors of pathological jaundice due to $\mathrm{ABO}$ hemolytic disease International Journal of Pharma \& Bio Sciences;JulSep2013, 4 (3) pB-125-130.

6. Eder F.A,Manno SC.Alloimmune Hemolytic Disease of the Fetus and Newborn In Greer PJ,Foerster J,Lukens NJ,Rodgers MG,Paraskevas F,Glader B.Wintrobes Clinical Hematology 11 edn volume 1,Philadelphia :.Llippincott Williams and Wilkins,2004.chapter 36p 1185-1186

7. Mentzer WC, Glader BE. Erythrocyte disorder in infancy. In Avery's disease of the newborn. Taruseh HW, Ballard RD Eds. 7thEdn. Philadelphia, WB Saunders Co. 1998:1080-1111

8. Vinod K. Bhutani, Lois Johnson, Emidio M. Sivieri Predictive Ability of a Predischarge Hour-specific Serum Bilirubin for Subsequent Significant Hyperbilirubinemia in Healthy Term and Near-term Newborns, Pediatrics 1999 Jan, 103 (1);6- 14

9. Ip S, Chung M, Kulig J, O'Brien R, Sege R, Glicken S, Maisels MJ, Lau J American Academy of Pediatrics Subcommittee on Hyperbilirubinemia An evidencebased review of important issues concerning neonatal hyperbilirubinemia ,Pediatrics. 2004 Jul;114(1):130-53.

10. Perry BW, Doumas BT, Bayse DD, Butler T, Cohen A, Fellows W, Garber CC, Howell B, Koch T, Krishnamurthy S, Louderback A, McComb RB, Miller D, Miller RR, Rand RN, Schaffer R.A candidate reference method for determination of bilirubin in serum. Test for transferability. Clin Chem. 1983 Feb;29(2):297-301

11. American Academy of Pediatrics Subcommittee on Hyperbilirubinemia Management of hyperbilirubinemia in the newborn infant 35 or more weeks of gestation,Pediatrics2004 Jul;114(1):297-316. 
12. Vinod K. Bhutani Phototherapy to Prevent Severe Neonatal Hyperbilirubinemia in the Newborn Infant 35 or More Weeks of Gestation, Pediatrics 2011 September 128(4):1046-52 S DOI: 10.154 .

13. Martin.R, Cloherty JP. Neonatal Hyberbilirubinemia. In cloherty J.P, Eichenwald E .C, Stark A.R. Manual of Neonatal Care.6 edn, Philadelphia: Lippincott Williams and Wilkins, 2008.chapter 18p210-211

14. Venkatamurthy M1, Murali S.M2, Mamatha S3 A comparison study: cord serum albumin is compared with cord serum bilirubin as a risk indicator in predicting neonatal jaundice Journal of Evolution of Medical and Dental Sciences 2014 April 3(15) Page: 4017-4022. DOI:10.14260/ jemds/2014/2393
15. Amar. Taksande, Krishna. Vihekar, Manish, et al. Prediction of the development of neonatal hyperbilirubinemia by increased umbilical cord blood bilirubin ,Indmedica Current Pediatric Research 2005 sep 9(1) $5-9$

16. Ben wood, Phyllis Culley, Claudia Roginski, Jean Powell, And John Waterhouse Factors affecting neonatal jaundice Archives of Disease in Childhood, 1979, 54, 111-115

17. G.K. Suresh, R.E. Clark Cost-effectiveness of strategies that are intended to prevent kernicterus in newborn infants Pediatrics,2004 october 114 (4) 917924

\section{How to cite this article?}

Maya Menon, Sreejyothi G, Raveendranath K' Incidence of early neonatal hyperbilirubinemia in ABO incompatibility and cord bilirubin as a predictor for phototherapy: Int J Pediatr Res 2016;3(4):221-227.doi:10.17511/ijpr.2016.i04.03. 